www.jmscr.igmpublication.org

Impact Factor 5.244

Index Copernicus Value: 83.27

ISSN (e)-2347-176x ISSN (p) 2455-0450

crossref DOI: _http://dx.doi.org/10.18535/jmscr/v4i9.81

Journal Of Medical Science And Clinical Research

\title{
Etiology of Primary Dislocation in Recurrent Anterior Shoulder Instability: A Cross-Sectional Study
}

\author{
Authors \\ Mohammad Ashraf Khan, Shiekh Ajaz Rafeeq, Mehmood-Ul-Hassan Mufti \\ Munir Farooq, Naseemul Gani, Hayat Ahmad Khan \\ Postgraduate, Department of Orthopaedics, Bone \& Joint Hospital \\ Government Medical College Srinagar INDIA
}

\begin{abstract}
Introduction: Shoulder joint is the most unstable and frequently dislocating joint because of its anatomy and biomechanics. In most patients shoulder instability occurs after a clear traumatic insult. According to one estimate, up to $96 \%$ of acute shoulder dislocations were traumatic in origin. It is sometimes difficult to identify a clear mechanism of injury that resulted in shoulder instability. This may be true in patients with underlying ligamentous laxity or in patients whose shoulder musculature has been deconditioned. For these patients, the onset of instability can be associated with minimal or no significant trauma. Some cases of instability are the result of a violent high-energy trauma, and may be associated with other soft-tissue or bony damage. The aim of this study was to look into the etiology of primary dislocation in our patient population so that a most suitable treatment option can be provided from a wide array of options possible.

Materials and Methods: This study was conducted in the Postgraduate Department of Orthopaedics, Bone \& Joint Hospital, Associated to Government Medical College Srinagar, and a Tertiary Care Referral Hospital from October 2013 to April 2016. 225 unselected patients of either gender in the age group of 20 to 40 years, attending to OPD or emergency Department, with recurrent anterior shoulder instability were asked about the mode of trauma at the time of their primary dislocation.

Results: Among 225 patients 189 were males and 36 were females. Right side, dominant side in all the patients, was involved in 180 (80\%) patients and left in 45 (20\%) patients. Traumatic etiology was found in 198 (88\%) patients and atraumatic etiology in 27 (12\%) patients.Direct trauma to shoulder caused by fall on affected shoulder or RTA accounted for $44 \%$ of cases and indirect trauma like fall on outstretched limb or lifting of heavy weight or overhead throwing activity accounted for $44 \%$ of cases. Mild trauma accounted for $12 \%$ of cases. So major traumatic event was a cause in majority of cases.

Conclusion: Majority of our patients had sustained macro traumatic event as a cause of their primary dislocation with 198 patients (88\%) having macro traumatic etiology and 27 patients (12\%) patients having micro traumatic or atraumatic etiology. Most striking difference in our patients compared to western population in terms of etiology is that most of the patients in west are high collision contact athletes.
\end{abstract}

Keywords: Recurrent anterior shoulder instability, Primary dislocation, high contact collision sports. 


\section{Introduction}

Shoulder joint is the most unstable and frequently dislocating joint because of its anatomy and biomechanics. It accounts for $50 \%$ of all dislocations with $2 \%$ incidence in general population ${ }^{[1]}$. The diagnosis and the treatment of glenohumeral instability have been well documented in history of mankind. Prehistoric drawings of $1200 \mathrm{BCE}$ show figures that are extremely similar to a shoulder reduction manoeuvre commonly used today.

Factors affecting probability of recurrent dislocations;

1. Age-younger the age greater the risk

2. Return to contact or collision sports

3. Hyperlaxity

4. Presence of significant bony defect in glenoid or humeral head

In most patients shoulder instability occurs after a clear traumatic insult. According to one estimate, up to $96 \%$ of acute shoulder dislocations were traumatic in origin. ${ }^{[2]}$ It is sometimes difficult to identify a clear mechanism of injury that resulted in shoulder instability. This may be true in patients with underlying ligamentous laxity or in patients whose shoulder musculature has been deconditioned. For these patients, the onset of instability can be associated with minimal or no significant trauma. Some cases of instability are the result of a violent high-energy trauma, and may be associated with other soft-tissue or bony damage.

Although direct trauma to the shoulder girdle can result in subluxations or dislocations, instability usually occurs after an indirect force is applied to the shoulder. As such, unexpected force to the arm when the glenohumeral joint is in a susceptible position is often the cause of instability. For many anterior shoulder dislocations, the instability is typically in some combination of abduction, external rotation, and extension when a sudden load is applied to the arm. The aim of this study was to know about the common modes of injury leading to primary dislocation of shoulder in patients with recurrent anterior shoulder instability.

\section{Materials and Methods}

This study was conducted in the Postgraduate Department of Orthopaedics, Bone \& Joint Hospital, Associated to Government Medical College Srinagar, and a Tertiary Care Referral Hospital from October 2013 to April 2016. This was a prospectivestudy in which 225 unselected patients of either gender in the age group of 20 to 40 years with recurrent anterior shoulder instability were asked about the mode of trauma at the time of their primary dislocation. Every patient attending to emergency or out-patient departments was asked about mode of trauma at the time of initial dislocation, whether participating in any sports activity, type of intervention for reduction, number of subsequent dislocations, ease with which reduction was achieved after subsequent episodes and any neurovascular complications due to trauma or reduction. Most of the patients were seen in emergency with a fresh episode of dislocation in whom initial radiographs were taken to confirm the diagnosis. Closed reduction was done usually without the need of any sort of sedation or anaesthesia. A record book was maintained to enter all details of the patients with emphasis on mode of injury at the time of primary dislocation.

\section{Results}

189 male and 36 female patients presenting to emergency or out-patient departments of Postgraduate Department of Orthopaedics, Bone \& Joint Hospital, Associated to Government Medical College Srinagar, a Tertiary Care Referral Hospital, were asked about the mode of trauma at primary dislocation. Right side, dominant side in all the patients, was involved in $180(80 \%)$ patients and left in $45(20 \%)$ patients. Traumatic etiology was found in 198 (88\%) patients and atraumatic etiology in $27(12 \%)$ patients. Direct trauma to shoulder caused by fall on affected shoulder or RTA accounted for $44 \%$ 
of cases and indirect trauma like fall on outstretched limb or lifting of heavy weight or overhead throwing activity accounted for $44 \%$ of cases. Mild trauma accounted for $12 \%$ of cases. So major traumatic event was a cause in majority of cases.

Table 1: Age Distribution

\begin{tabular}{|l|l|l|}
\hline Age(years) & Number & \%age \\
\hline $20-25$ & 113 & 50 \\
\hline $25-30$ & 76 & 34 \\
\hline $30-35$ & 18 & 8 \\
\hline $35-40$ & 18 & 8 \\
\hline Total & 225 & 100 \\
\hline
\end{tabular}

Table 2: Gender Distribution

\begin{tabular}{|l|l|l|}
\hline Gender & Number & \%age \\
\hline Male & 189 & 84 \\
\hline Female & 36 & 16 \\
\hline Total & 225 & 100 \\
\hline
\end{tabular}

Table 3: Mode of Injury

\begin{tabular}{|l|l|l|}
\hline Mode of injury & Number & \%age \\
\hline Traumatic & 198 & 88 \\
\hline Atraumatic & 27 & 12 \\
\hline Total & 225 & 100 \\
\hline
\end{tabular}

Table 4: Mode of Injury

\begin{tabular}{|l|l|l|}
\hline Mode of Injury & Number & \%age \\
\hline Fall on affected shoulder & 113 & 40 \\
\hline Overhead throwing activity & 76 & 24 \\
\hline Fall on outstretched limb & 18 & 12 \\
\hline Mild trauma & 18 & 12 \\
\hline Lifting of heavy weight & & 8 \\
\hline RTA & & 4 \\
\hline Total & 225 & 100 \\
\hline
\end{tabular}

Table 5: Athletic Participation

\begin{tabular}{|l|l|l|}
\hline Type of Sport & Number & \%age \\
\hline High Collision & 25 & 11 \\
\hline Recreational & 75 & 33 \\
\hline None & 125 & 56 \\
\hline Total & 225 & 100 \\
\hline
\end{tabular}

\section{Discussion}

In literature it is widely reported that $96 \%$ of acute shoulder dislocations are traumatic in origin ${ }^{[2]}$. In our series 198 of patients (88\%) sustained trauma at the time of primary dislocation and 27 of 225 patients sustained either trivial or no significant trauma on primary dislocation.

Sameul L. Schmid et. al., ${ }^{[3]} 2012$ reported49 patients with recurrent anterior shoulder instability. The reason for the first dislocation was a traumatic event in forty-six cases (94\%) and minor trauma in three (6\%).Sports injury was found in majority of patients

Matthes $G$ et. al., ${ }^{[4]} 2007$ evaluated 100 patients with recurrent anterior shoulder instability and assessed overall stability and function of shoulder. 83 of 100 cases had a traumatic etiology of their primary dislocation while 17 of 100 patients sustained no or trivial trauma at the time of primary dislocation. Overhead throwing was the commonest cause and most commonly affected population was competitive athletes.

Singer et al ${ }^{[5]} 1995$ evaluated 14 patients of recurrent anterior instability. 13 of 14 (92.85\%) patients had traumatic etiology while 1 of 14 $(7.15 \%)$ patients sustained atraumatic initial dislocation. Almost all these patients were sports persons and sustained trauma while playing.

Matton D et. al., ${ }^{[6]} 1992$ evaluated 30 patients with recurrent anterior shoulder instability.83.3\% patients had traumatic etiology while 16.7 had atraumatic instability. Trauma was sustained while playing in competitive high collision sports in most of the patients.

\section{Conclusion}

Majority of our patients had sustained macrotraumatic event as a cause of their primary dislocation with 198 patients (88\%) having macrotraumatic etiology and 27 patients (12\%) patients having microtraumatic or atraumatic etiology. Most striking difference in our patients compared to western population in terms of etiology is that most of the patients in west are high collision contact athletes. Trauma was sustained most of the times while playing. In our study majority of the patients were young but nonathletes. So it is highly possible that pattern of injury to shoulder joint in our patients will be 
different from that of western population. Treatment options and criteria for patient satisfaction will vary as stability is primary need in our patients. In west stability as well as function of joint are both required as patients want to return back to their athletic activities.

\section{References}

1. Burkhart SS, Morgan CD, Kibler WB: The disabled throwing shoulder, spectrum of pathology, part I:pathoanatomy and biomechanics, Arthroscopy sub 19:404, 2003

2. Rowe C. Prognosis in dislocations of the shoulder. J Bone Joint Surg 1956;38-A(5): 957-977

3. Samuel L. Schmid, MSc, Mazda Farshad, MD, Sabrina Catanzaro, RRN, and Christian Gerber, MD, FRCSEd(Hon): The Latarjet Procedure for the Treatment of Recurrence of Anterior Instability of the Shoulder After Operative Repair; Bone Joint Surg Am. 2012; 94:e75(1-7)

4. G. Matthes, V. Horvath, J. Seifert et al., "Oldie but goldie: Bristow-Latarjet procedure for anterior shoulder instability," Journal of Orthopaedic Surgery, vol. 15, no. 1, pp. 4-8, 2007.

5. G. C. Singer, P. M. Kirkland, and R. J.H. Emery, "Coracoid transposition for recurrent anterior instability of the shoulder. A 20-year follow-up study," Journal of Bone and Joint Surgery B, vol. 77, no. 1, pp. 73-76, 1995.

6. Matton D, Van Looy F, Geens S (1992) Recurrent anterior dislocations of the shoulder joint treated by the BristowLatarjet procedure. Historical review, operative technique and results. Acta Orthop Belg 58(1):16-22. 